Eficiência hidrológica de telhados verdes para a escala de loteamentos residenciais José Eduardo Alamy Filho, Igor Brito Costa Barcelos e Manna, Nágela Aparecida de Melo, Ana Clara Mendes Caixeta

\title{
EFICIÊNCIA HIDROLÓGICA DE TELHADOS VERDES PARA A ESCALA DE LOTEAMENTOS RESIDENCIAIS
}

\section{Hydrological efficiency of green roofs for residential neighborhoods scale}

José Eduardo Alamy Filho zealamy@yahoo.com.br

Universidade Federal de Uberlândia, Uberlândia, Minas Gerais, Brasil

Igor Brito Costa Barcelos e Manna igor_bcmanna@hotmail.com

Universidade Federal de Uberlândia, Uberlândia, Minas Gerais, Brasil

Nágela Aparecida de Melo nagelamelo@hotmail.com

Universidade Federal de Uberlândia, Uberlândia, Minas Gerais, Brasil

Ana Clara Mendes Caixeta

anaclara_caixeta@hotmail.com

Universidade Federal de Uberlândia, Uberlândia, Minas Gerais, Brasil

Artigo recebido em 19/01/2015 e aceito para publicação em 18/02/2016

RESUMO: O presente trabalho teve o objetivo de estimar o comportamento de um conjunto de telhados verdes em relação à sua capacidade de inibição do escoamento superficial, utilizando a escala espacial de loteamento. A eficiência hidrológica dos telhados verdes foi avaliada em função da redução relativa do volume de escoamento superficial, comparando a situação de implantação da cobertura permeável, em todas as edificações de um loteamento, com a situação de telhado convencional impermeável. As estimativas teóricas utilizaram um modelo hidrológico, com imposição de diversos cenários de precipitação. O efeito das chuvas foi introduzido pela equação de intensidade, duração e frequência local e por distribuições temporais sintéticas. Os tipos e usos do solo foram considerados a partir do parâmetro curva-número. A metodologia proposta foi aplicada para um condomínio residencial situado na cidade de Uberlândia, Minas Gerais. Os resultados das simulações hidrológicas indicaram que a implantação de telhados verdes aponta para reduções expressivas do volume de escoamento superficial. Neste contexto, estimaram-se eficiências entre 2,02\% e 55,67\%. Para condições de solo inicialmente seco, que são comuns após estiagens, foi prevista uma eficiência hidrológica média de 40,35\%. A despeito disto, este índice reduz-se para 10,44\% em situações de saturação iminente, decorrentes de chuvas anteriores sucessivas. A despeito da sua dependência da umidade antecedente do solo, este potencial de redução do escoamento superficial é considerável. Assim, a implantação de telhados verdes contribui para atenuar as vazões de pico geradas na saída do loteamento, aliviando o sistema público de drenagem e, num contexto mais amplo, reduzindo os riscos de enchentes ribeirinhas nos fundos de vale.

Palavras-chave: drenagem urbana; telhados verdes; escoamento superficial. 
ABSTRACT: The purpose of this paper is to estimate the behavior of a set of green roofs in relation to its ability to inhibit runoff, using the spatial scale of residential neighborhoods. The hydrological efficiency of green roofs was evaluated based on the relative reduction of runoff volume, comparing the situation of implementation of permeable coverage, in all buildings, with the situation with impermeable roof. A hydrologic model was applied, with various scenarios of precipitation. This effect was introduced by rainfall equation and synthetic temporal distributions. Types and land uses were considered from the curve number parameter. The proposed methodology was applied to a residential condominium located in the city of Uberlândia, Minas Gerais. The results indicate that the implementation of green roofs points to significant reductions in the volume of runoff. In this context, it is estimated efficiencies between $2.02 \%$ and $55.67 \%$. For initially dry soil conditions, which are common after drought, an average hydrological efficiency of $40.35 \%$ was expected. However, this ratio is reduced to $10.44 \%$, in situations of imminent saturation, previous successive rainfall events. Despite its dependence on antecedent soil moisture, this reduction of runoff is considerable. Thus, the implementation of green roofs helps to mitigate peak flows generated at the output of neighborhood, relieving the public drainage system and, in a broader context, reducing the risk of flooding in the valley bottoms.

Keywords: urban drainage; green roofs; runoff.

\section{INTRODUÇÃO}

A crescente ocupação de microbacias urbanas condiciona o aumento da impermeabilização do solo, amplificando a magnitude do escoamento superficial gerado por eventos de precipitação. Neste aspecto, além da impermeabilização, há todo um conjunto de obras, como galerias e retificações de canais, as quais também tendem a acelerar o escoamento, reduzindo os tempos de concentração das microbacias e fazendo com que as águas cheguem mais rapidamente aos fundos de vale. O resultado global reflete-se no aumento das vazões veiculadas nos cursos de água e na precocidade da ocorrência dos picos de cheia. Em casos extremos, verifica-se o transbordamento da calha principal dos canais urbanos, de forma que a água passa a avançar lateralmente pelas várzeas que, na maioria das vezes, já apresentam ocupação histórica. A impermeabilização de conjuntos de lotes também sobrecarrega o sistema de microdrenagem, constituído por sarjetas, bocas de lobo e galerias de água pluvial. Neste sentido, quando estes elementos não conseguem veicular os grandes volumes de água, surgem casos críticos de alagamentos em áreas relativamente distantes dos fundos de vale.

Uma das soluções para a redução destes problemas consiste na aplicação de técnicas de desenvolvimento de baixo impacto (low impact development - LID), as quais propiciam redução ou atenuação do escoamento superficial dentro da própria microbacia. A LID é uma prática de drenagem urbana sustentável que baseia-se em princípios como a manutenção de paisagens naturais e na redução de áreas impermeáveis. Dentre estas alternativas, citam-se o uso de pavimentos permeáveis, jardins de infiltração domiciliares ou condominiais, além da implantação de telhados verdes.

A concepção construtiva de um telhado verde pode apresentar uma série de camadas sobrepostas à laje da edificação, mas, de uma forma geral, os elementos básicos são a impermeabilização da laje, o meio suporte poroso e a vegetação. A camada superior de vegetação normalmente é rasteira, constituída por gramíneas ou variações, de forma que as raízes não sejam muito longas, fator que exigiria um meio suporte de grande profundidade, encarecendo o custo de execução do telhado e, consequentemente, o custo global da edificação.

Segundo Stovin; Dunnett; Hallam (2007), os telhados verdes constituem um sistema de drenagem urbana sustentável que tem a particularidade de não exigir grandes áreas, além da própria projeção horizontal de cada edificação. Isto torna sua aplicação compatível com ambientes urbanos densamente ocupados, nos quais há poucas áreas permeáveis remanescentes. Palla et al. (2008) complementam esta ideia ressaltando a importância de readaptar o gerenciamento de águas pluviais dentro do próprio 
Eficiência hidrológica de telhados verdes para a escala de loteamentos residenciais

José Eduardo Alamy Filho, Igor Brito Costa Barcelos e Manna, Nágela Aparecida de Melo, Ana Clara Mendes Caixeta

ambiente da edificação, de forma que os telhados possam contribuir beneficamente com o sistema de drenagem e não ampliar os problemas de enchentes. Stovin; Dunnett; Hallam (2007) ainda destacam o valor estético das coberturas verdes para a arquitetura urbana e o seu potencial de aumentar a biodiversidade. Baldessar (2012) salienta que as principais justificativas ambientais para implantação de telhados verdes vinculam-se à melhoria da qualidade do ar, à redução do efeito de ilhas de calor nos centros urbanos e, finalmente, à redução das vazões nas redes coletoras de água pluvial. É neste contexto que as coberturas permeáveis apresentam certa eficiência hidrológica, aqui definida como a redução proporcional do volume de escoamento superficial quando comparadas com coberturas convencionais impermeáveis (telhas ou lajes). Quando implantados em todas as edificações de um loteamento, os telhados verdes têm potencial de aliviar o sistema de microdrenagem urbana durante eventos de chuva, diminuindo riscos de alagamentos nas ruas e contribuindo, num contexto mais amplo, para minimizar as enchentes de fundo de vale.

Alguns dos principais estudos relacionados com a eficiência hidrológica das coberturas permeáveis focam-se basicamente na realização de experimentos com protótipos de telhados em escala reduzida, monitorando os volumes de água precipitados e aqueles coletados por drenos inferiores. Nestes casos, as fontes de água podem ser precipitações reais ou artificiais, simuladas com aspersores. De uma forma geral, estes experimentos têm demonstrado elevados níveis de atenuação do escoamento superficial, quando protótipos de telhados verdes são confrontados com protótipos de telhados impermeáveis. Para citar exemplos, Kolb (2004) encontrou reduções de escoamento superficial anual da ordem de 45 a 70\%. Moran et al. (2004) relataram $60 \%$ de retenção da precipitação total e até $85 \%$ de redução da vazão de pico. Palla et al. (2008) monitoraram onze eventos de chuvas reais, encontrando retenções da ordem de $34 \%$ dos volumes precipitados, com redução média de $56,9 \%$ para a vazão de pico. Baldessar (2012) identificou escoamento superficial em torno de $30,7 \%$ do volume de água precipitado, levando em conta eventos reais entre novembro de 2011 e fevereiro de 2012, para a região de Curitiba. Trabalhos como o de Johnston et al. (2004) chamam a atenção para os efeitos sazonais. Tais autores notaram que o escoamento superficial pode aumentar em até $100 \%$ com chuvas prolongadas. Este efeito decorre da redução do potencial de infiltração em função do aumento da umidade e saturação iminente do substrato poroso do telhado.

Uma outra forma de quantificar a eficiência hidrológica dos telhados verdes consiste na aplicação de modelos teóricos chuva-vazão. Estas simulações podem ser aplicadas tanto em escala de protótipos, quanto na escala de loteamentos ou bairros inteiros. Baldessar (2012) utilizou o programa Green Roof, fornecido pela Inter Universitare Programme in Water Resources Engineering (IUPWARE), para simular a eficiência hidrológica do seu protótipo de telhado verde. No caso, a autora verificou volume escoamento superficial da ordem de $33,4 \%$ do volume de chuva, resultado muito próximo das suas medições experimentais. Palla et al. (2008) utilizaram o modelo EPA Storm Management Model (SWMM), desenvolvido por Hubber e Dickinson (1992), para simular o efeito de coberturas permeáveis implantadas hipoteticamente nas quinhentas edificações da microbacia urbana de Colle Ometti, em Gênova, Itália. No referido estudo, os autores encontraram redução de $5 \%$ do pico de vazão, para um cenário de conversão de $10 \%$ dos telhados impermeáveis em telhados verdes. Quando a substituição foi total, as vazões de pico reduziram-se em até $51 \%$. Partindo desta linha de estudos, o objetivo do presente artigo é estimar a eficiência de telhados verdes na redução do volume de escoamento superficial, utilizando simulações com modelo hidrológico aplicado para a escala espacial de loteamento.

\section{MATERIAL E MÉTODOS}

\section{Recorte espacial do estudo}

No presente artigo, a eficiência da implantação do telhado verde foi analisada em função da redução do volume de escoamento superficial, em comparação com o cenário real de telhados convencionais. Para esta estimativa, utilizou-se um modelo hidrológico de transformação de chuva em vazão, propiciando a avaliação expedita da redução de escoamento superficial e atenuação dos hidrogramas gerados em escala 
Eficiência hidrológica de telhados verdes para a escala de loteamentos residenciais

José Eduardo Alamy Filho, Igor Brito Costa Barcelos e Manna, Nágela Aparecida de Melo, Ana Clara Mendes Caixeta

de loteamento. Nesta perspectiva, a área de estudo é tratada como uma bacia de contribuição, substituindo-se a projeção horizontal dos telhados convencionais por telhados verdes relvados. Trata-se, pois, de uma metodologia geral, aplicável a loteamentos, bairros ou até mesmo a malhas urbanas completas.

Para a delimitação do recorte espacial deste estudo, optou-se por um condomínio projetado com edificações padronizadas, permitindo uma identificação mais precisa das áreas de telhado. Assim, o local selecionado foi o condomínio The Palms Houses \& $C l u b$, localizado na zona sul da cidade de Uberlândia, Minas Gerais (Figura 1).

Figura 1 - Loteamento escolhido para aplicação do estudo.

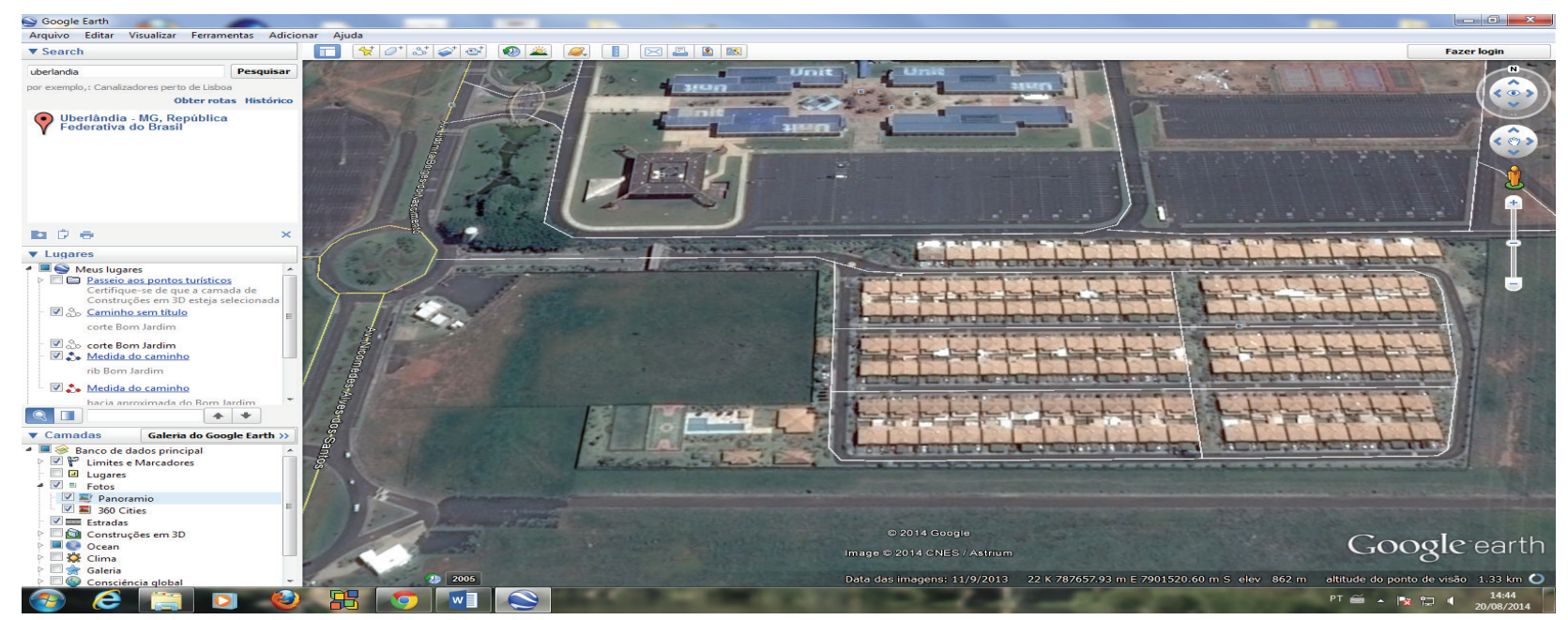

Fonte: Google Earth, 2014.

Note-se que a substituição das áreas de telhado convencional pela cobertura verde, reduz consideravelmente o total de áreas impermeáveis. Com isto, o potencial de transformação de chuva em escoamento superficial também tende a reduzir-se. A consequência final é uma diminuição das vazões de água pluvial descarregadas pelo condomínio na rede coletora pública. A redução das vazões de pico e o decorrente atraso nos instantes em que ocorrem as vazões máximas contribuem não só para aliviar o sistema de microdrenagem (sarjetas, bocas de lobo e galerias), como também para evitar sobrecargas no sistema de macrodrenagem (canais urbanos em fundos de vale), reduzindo concomitantemente os riscos de alagamentos em áreas altas e de enchentes em áreas baixas.

\section{Modelo hidrológico}

Neste trabalho, foi utilizado o Método Santa Bárbara (STUBCHAER, 1980), cujo produto final, segundo Tomaz (2002), é a distribuição temporal de vazões (hidrograma) geradas por uma precipitação para uma determinada bacia contribuinte. Este método considera o efeito de armazenamento, o qual pode ser interpretado como a parcela da chuva excedente (escoamento superficial) que fica temporariamente retida na bacia e que chegará ao ponto final e mais baixo da área com certo retardo.

Em linhas gerais, o Método Santa Bárbara é alimentado com características da bacia - aqui equivalente à área intramuros do loteamento - e com características da precipitação. Dentre os aspectos vinculados ao loteamento, citam-se o tipo de solo superficial, uso do solo, condições de umidade antecedente da superfície e o tempo de concentração. Dentre as características da precipitação, citam-se a duração e sua distribuição temporal (hietograma). A intensidade da precipitação também é um fator necessário, normalmente quantificado por equações de chuva que também relacionam, além da duração, o tempo de recorrência da tormenta. A Figura 2 ilustra o fluxograma utilizado pelo Método Santa Bárbara. 
Eficiência hidrológica de telhados verdes para a escala de loteamentos residenciais José Eduardo Alamy Filho, Igor Brito Costa Barcelos e Manna, Nágela Aparecida de Melo, Ana Clara Mendes Caixeta

Figura 2 - Principais conversões utilizadas pelo Método Santa Bárbara.

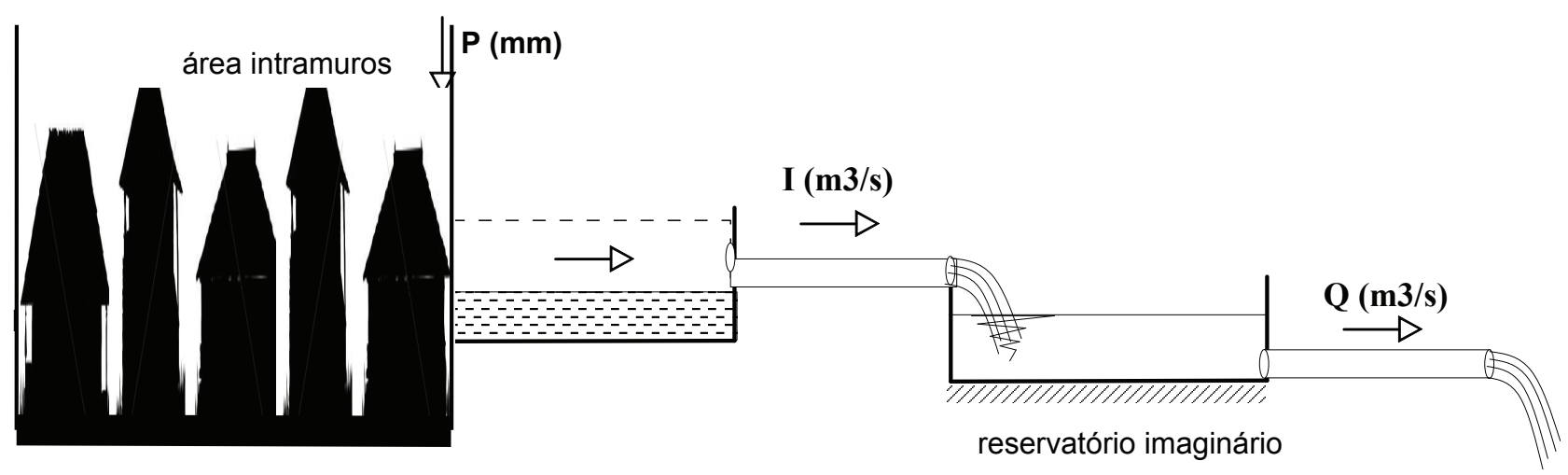

Org. dos autores.

O modelo é alimentado pela precipitação $(P)$ incidente sobre a área intramuros do condomínio. A conversão de chuva em escoamento superficial $(P e)$ depende da magnitude das áreas impermeáveis, das características do solo relativas ao potencial de infiltração, da umidade antecedente e do uso e ocupação. Estas variáveis são traduzidas pelo parâmetro curva-número $(C N)$. É justamente a alteração do número $C N$ do loteamento, proporcionada substituição dos telhados convencionais pelos telhados verdes, que afetará o hidrograma final, efeito resultante da mudança no tempo de concentração da bacia e da alteração do escoamento superficial gerado pela chuva. Para a estimativa do escoamento superficial (ou chuva excedente), utilizou-se a metodologia do Soil Conservation Service (SCS). A infiltração (Inf) pode ser estimada como a diferença entre a precipitação e a chuva excedente. O escoamento superficial é convertido na vazão de entrada $(I)$ em um reservatório virtual, que é introduzido para modelar os efeitos de translação e armazenamento temporário da água na bacia de contribuição. Após o amortecimento do escoamento no reservatório imaginário, calculam-se as vazões descarregadas $(Q)$ no final do loteamento. A representação gráfica da variação temporal destas vazões, durante e imediatamente após eventos de precipitação, fornece o hidrograma. Os volumes de escoamento superficial gerados pela chuva podem ser obtidos por integração numérica, calculando-se a área situada abaixo da linha do hidrograma.

O Método Santa Bárbara demanda a seguinte sequência de cálculos:

Precipitação total $(\mathrm{mm}): \quad P=i \cdot t_{d}$

Potencial máximo de retenção da área de contribuição $(\mathrm{mm}): \quad S=\frac{25400}{C N_{r}}-254$

Fração de área impermeável: $d=A_{\text {impermenene }} / A_{\text {total }}$

Coeficiente de retardo: $k_{r}=\frac{\Delta t}{2 \cdot t_{c}+\Delta t}$

Nas Equações (1) a (4), $i$ é a intensidade da precipitação, calculada a partir da equação de chuva do local e $t_{d}$ é a duração da tormenta; $S$ representa a máxima parcela de precipitação que pode ficar retida nas depressões do terreno, não contribuindo para a chuva excedente; ao passo que $\mathrm{CN}_{\mathrm{r}}$ é a curva número resultante da bacia contribuinte. Dentro da área intramuros do loteamento, a área total $\left(A_{\text {total }}\right)$ e a soma das áreas impermeáveis $\left(A_{\text {impermeável }}\right)$ devem ser contabilizadas em planta. O coeficiente de retardo $\left(k_{r}\right)$ representa o atraso do escoamento em chegar até o ponto onde a vazão é descarregada no sistema 
público de microdrenagem (seção de controle). Sua quantificação depende do tempo de concentração da área intramuros $\left(t_{c}\right)$, que é o tempo decorrido, após o início da chuva, para que todo o loteamento possa contribuir para a vazão na seção de controle.

A solução do modelo hidrológico requer a discretização do tempo total de simulação em incrementos $(D t)$. Desta forma, a cada passo de tempo, um procedimento iterativo deve ser resolvido, o que sugere a construção de um algoritmo computacional para solução das suas operações. Neste trabalho, o modelo hidrológico foi sistematizado em um programa escrito na linguagem Visual Basic aplicada ao Microsoft Excel. O hidrograma final é estimado pelo seguinte roteiro iterativo de operações:

Precipitação acumulada $(\mathrm{mm}): \quad P_{a c}^{t+\Delta t}=\% P_{a c} \cdot \frac{P}{100}$

Precipitação por faixa $(\mathrm{mm}): P_{f x}^{t+\Delta t}=P_{a c}^{t+\Delta t}-P_{a c}^{t}$

Chuva excedente acumulada $(\mathrm{mm})$ :

$$
P e_{a c}^{t+\Delta t}=\left\{\begin{array}{cll}
\frac{\left(P_{a c}^{t+\Delta t}-0,2 \cdot S\right)^{2}}{P_{a c}^{t+\Delta t}+0,8 \cdot S} & \text {, quando } & P_{a c}^{t+\Delta t}>0,2 \cdot S \\
0 & \text {,quando } & P_{a c}^{t+\Delta t} \leq 0,2 \cdot S
\end{array}\right.
$$

Chuva excedente por faixa $(\mathrm{mm}): P e_{f x}^{t+\Delta t}=P e_{a c}^{t+\Delta t}-P e_{a c}^{t}$

Intensidade de escoamento superficial nas áreas impermeabilizadas $(\mathrm{m} / \mathrm{s})$ :

$$
I_{\text {impermecie }}^{t+\Delta t}=10^{-3} \cdot P_{f x}^{t+\Delta t} / \Delta t
$$

Intensidade de escoamento superficial nas áreas permeáveis $(\mathrm{m} / \mathrm{s})$ :

$$
I_{\text {permeatel }}^{t+\Delta t}=10^{-3} \cdot P e_{f x}^{t+\Delta t} / \Delta t
$$

Vazão de entrada no reservatório imaginário $\left(\mathrm{m}^{3} / \mathrm{s}\right)$ :

$$
I^{t+\Delta t}=\left\{I_{\text {impermeciel }}^{t+\Delta t} \cdot d+I_{\text {permecivel }}^{t+\Delta t} \cdot(1-d)\right\} \cdot A_{\text {total }}
$$

Vazão de saída do reservatório imaginário $\left(\mathrm{m}^{3} / \mathrm{s}\right)$ :

$$
Q^{t+\Delta t}=Q^{t}+k_{r} \cdot\left(I^{t}+I^{t+\Delta t}-2 \cdot Q^{t}\right)
$$

Nas Equações (5) a (12), os índices $t$ e $t+D t$ indicam, respectivamente, $\mathrm{o}$ instante anterior e o instante futuro do laço iterativo de cálculo. Na Equação (5), $P$ é a altura pluviométrica total da chuva, sendo que a porcentagem de precipitação exercida $\left(\% P_{a c}\right)$ até o instante $t+D t$ pode ser extraído do hietograma da tormenta. A Equação (7) exprime o cálculo da chuva excedente pelo método SCS. Nota-se que, de acordo com esta metodologia, o escoamento superficial somente surge quando a precipitação acumulada supera $20 \%$ do potencial máximo de retenção da bacia. Nas Equações (9) e (10), o passo de tempo (Dt) deve ser introduzido em segundos e o fator $10^{-3}$ faz a conversão, da precipitação e da chuva excedente por faixa, de milímetros para metros. Na Equação (11), a área intramuros $\left(A_{\text {total }}\right)$ deve ser inserida em metros 
Eficiência hidrológica de telhados verdes para a escala de loteamentos residenciais José Eduardo Alamy Filho, Igor Brito Costa Barcelos e Manna, Nágela Aparecida de Melo, Ana Clara Mendes Caixeta

quadrados. Isto permite obter a vazão de entrada no reservatório virtual $(I)$ em metros cúbicos por segundo. Os resultados da Equação (12) fornecem as vazões $(Q)$ que compõem o hidrograma gerado no loteamento. Note-se que o efeito de amortecimento é levado em conta pelo coeficiente de retardo $\left(k_{r}\right)$.

\section{Parâmetros de precipitação}

Dentre os parâmetros de precipitação, que foram necessários para alimentar as simulações deste trabalho, destaca-se a equação de chuva local, a dis-

$$
i=\frac{35,58 \cdot T_{r}^{0,179}}{\left(t_{d}+16\right)^{0,879}}
$$

Na Equação (13), a intensidade de precipitação ( $i$ ) é obtida em mm/min, para tempos de recorrência $(T r)$ inseridos em anos e durações $\left(t_{d}\right)$ inseridas em minutos. Nas simulações deste trabalho, os tempos de recorrência foram fixados entre 6 meses e 100 anos, com a imposição de chuvas curtas, da ordem de minutos, até eventos mais longos, da ordem de várias horas.

Ainda que Francischet (2012) tenha levantado as distribuições temporais das precipitações anuais mais críticas - com maiores alturas pluviométricas tribuição temporal da tormenta, além de sua duração e tempo de recorrência.

As equações de chuva permitem relacionar a intensidade de chuvas máximas, verificadas em uma determinada região, com a duração do evento e a probabilidade do mesmo ser igualado ou superado dentro de certo período de tempo. Estas expressões são bastante utilizadas em dimensionamentos e na verificação do desempenho de sistemas de drenagem urbana. Neste caso, utilizou-se a equação de chuva para o município de Uberlândia, elaborada por Francischet e Alamy Filho (2011), a partir de dados pluviográficos:

- para a cidade de Uberlândia, entre os anos de 1996 e 2010, estes hietogramas não foram utilizados no presente trabalho. Esta opção é justificável, pois os referidos levantamentos não evidenciaram um padrão de distribuição destas chuvas máximas ao longo do tempo, algo também previsível pela aleatoriedade associada ao fenômeno de precipitação. Por isto, as curvas sintéticas de Huff com $50 \%$ de probabilidade de ocorrência, ilustradas pela Figura 3, foram aplicadas neste artigo. 
Figura 3 - Hietogramas adimensionais de Huff utilizados para simular a distribuição temporal das chuvas.

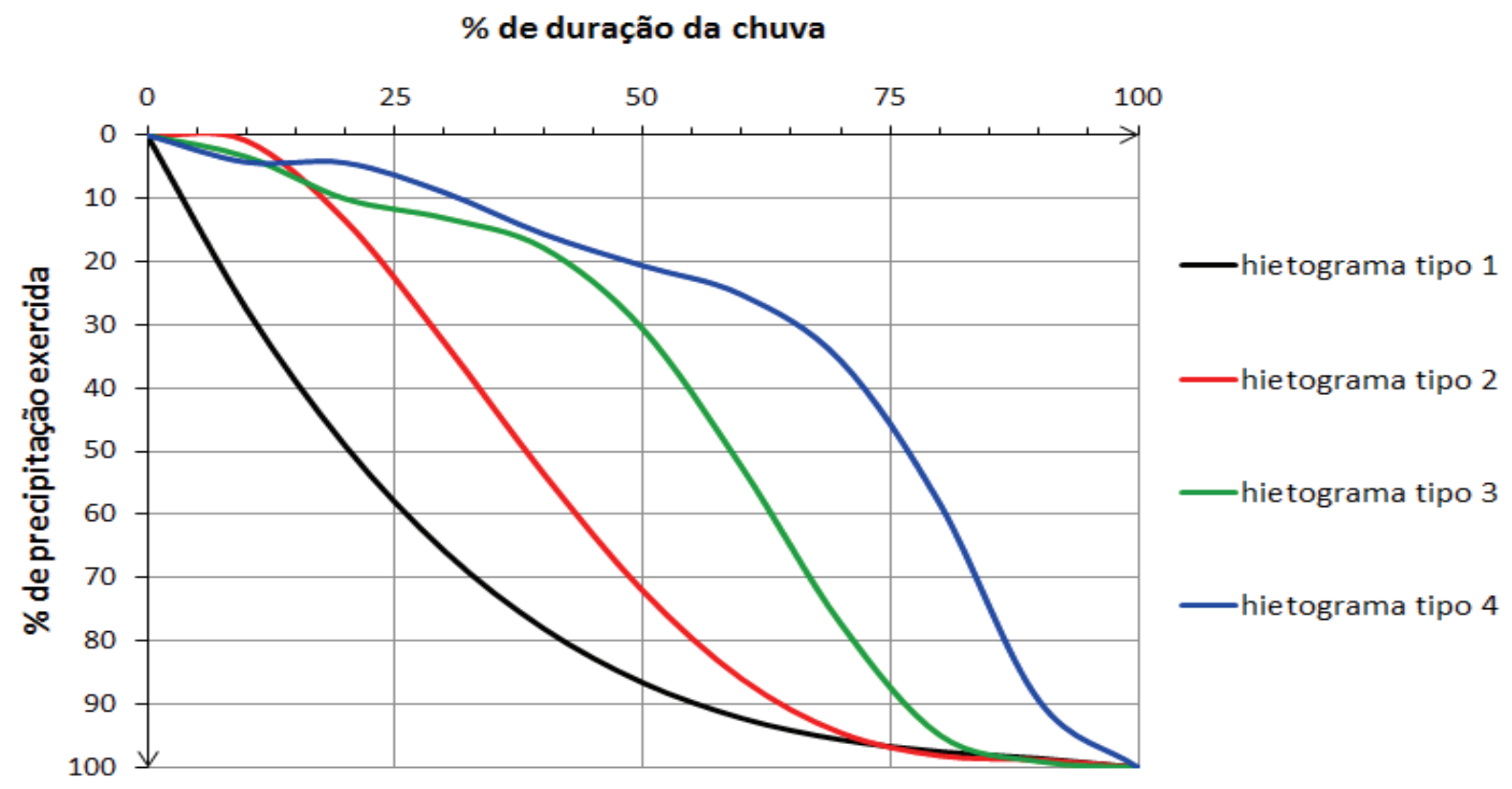

Org. dos autores.

Neste sentido, as distribuições temporais foram classificadas, no presente trabalho, como:

- Hietograma tipo 1, para o primeiro quartil: pico de chuva antes de $25 \%$ da duração (chuva concentrada no início do evento).

- Hietograma tipo 2, para o segundo quartil: pico de chuva entre $25 \%$ e $50 \%$ da duração.

- Hietograma tipo 3, para o terceiro quartil: pico de chuva entre $50 \%$ e $75 \%$ da duração.

- Hietograma tipo 4, para o quarto quartil: pico de chuva depois de $75 \%$ da duração (chuva concentrada no final do evento).

\section{Curva número resultante}

A curva número $(\mathrm{CN})$ de uma área é um parâmetro adimensional utilizado pelo SCS que pode, em tese, variar de 0 a 100. Quanto maior o seu valor, maior é a possibilidade da precipitação se transformar em escoamento superficial. O número $\mathrm{CN}$ depende basicamente do tipo de solo superficial, aqui relacionado com o teor de material argiloso e com a capacidade de infiltração, do uso do solo e das suas condições de umidade antecedente.

O tipo de solo predominante no local de estudo foi caracterizado de acordo com o estudo de Fonseca; Nishiyama (2003), como solo tipo D, com uma grande quantidade de argila, predominante nos latossolos álicos ou distróficos. O SCS classifica os solos nos tipos A, B, C e D, sendo que os solos D são aqueles com maior teor de material argiloso (30 a 40\% de argila total) e com menor capacidade mínima de infiltração (0 a $1,27 \mathrm{~mm} / \mathrm{h}$ ).

Como o estudo foi aplicado a um condomínio de casas padronizadas, não foram constatadas muitas variações nas formas de uso do solo. Em geral, as áreas impermeáveis consistem de arruamentos e vias asfaltadas com drenagem de águas pluviais, parque de estacionamento, telhados e concreto, cujo CN é 98. A partir da planta do loteamento, foram levantadas as áreas específicas de cada ambiente, utilizando o 
Eficiência hidrológica de telhados verdes para a escala de loteamentos residenciais José Eduardo Alamy Filho, Igor Brito Costa Barcelos e Manna, Nágela Aparecida de Melo, Ana Clara Mendes Caixeta

programa AutoCad. Os resultados deste levantamento relacionaram: 74 casas com $64,58 \mathrm{~m}^{2}$ de telhado e $6,72 \mathrm{~m}^{2}$ de área impermeável externa; 188 casas com $59,04 \mathrm{~m}^{2}$ de telhado e $6,72 \mathrm{~m}^{2}$ de área impermeável externa; espaço gourmet com 110,39 $\mathrm{m}^{2}$ de telhado; apoio para lazer com $110,39 \mathrm{~m}^{2}$ de telhado; apoio para funcionários com $68,67 \mathrm{~m}^{2}$ de telhado; salão de festas com 217,30 $\mathrm{m}^{2}$ de telhado; guarita com 101,47 $\mathrm{m}^{2}$ de telhado; quadra poliesportiva com $480 \mathrm{~m}^{2}$ de área impermeável; piscinas com 128,34 $\mathrm{m}^{2}$ de área impermeável; apoio de piscina com 13,32 $\mathrm{m}^{2}$ de telhado. Enfim, nas condições reais, a área total do loteamento é de $59.535 \mathrm{~m}^{2}$, com $16.499,98 \mathrm{~m}^{2}$ de área de telhado, $15.430,72 \mathrm{~m}^{2}$ de área impermeável (asfalto e concreto) e 27.604,30 $\mathrm{m}^{2}$ de espaço relvado. Estes levantamentos forneceram $31.930,7 \mathrm{~m}^{2}$ de área impermeável total.

$\mathrm{O}$ número $\mathrm{CN}$ resultante $\left(\mathrm{CN}_{\mathrm{r}}\right)$ é calculado como a média ponderada dos $\mathrm{CN}$ individuais, utilizando a área correspondente a cada uso do solo como peso de ponderação. Salienta-se que o $\mathrm{CN}_{\mathrm{r}}$ é inicialmente estimado para situações médias de umidade do solo (condição II). Todavia, conforme o solo esteja seco (condição I) ou na iminência de saturação (condição III), há a necessidade de se corrigir o valor inicial. Segundo McCuen (1998), a condição de solo úmido com iminência de saturação pode ocorrer com sequências de precipitações nos últimos cinco dias. Tem-se, neste último caso, a situação mais crítica, na qual o $\mathrm{CN}_{\mathrm{r}}$ é majorado, com amplificação do potencial de geração de escoamento superficial. A Tabela 1 resume os valores da curva número resultante para o condomínio analisado, considerando a situação real (com telhado convencional impermeável) e a situação hipotética (com telhado verde relvado).

Tabela 1 - Resumo das curvas número resultantes para três situações de umidade antecedente do solo e dois cenários de telhado.

\begin{tabular}{|c|c|c|}
\hline Condição de umidade do solo & \multicolumn{2}{|c|}{ CN resultante } \\
\cline { 2 - 3 } I - solo seco. & telhado convencional & telhado verde \\
\hline $\begin{array}{c}\text { II - condições médias do solo, utilizada como padrão para } \\
\text { levantamento da curva número. }\end{array}$ & 77,44 & 69,54 \\
\hline $\begin{array}{c}\text { III - solo úmido, com ocorrência de chuvas nos últimos 5 dias; } \\
\text { o solo está na iminência de saturação. }\end{array}$ & 89,65 & 84,67 \\
\hline
\end{tabular}

Org. dos autores.

\section{Tempo de concentração da área intramuros}

O tempo de concentração do condomínio foi calculado pelo Método de Germano e pelo Método de Schaake. Estes dois métodos clássicos levam em conta parâmetros geométricos da área de contribuição, como o comprimento axial e a declividade média, além de parâmetros relacionados com frações de áreas impermeabilizadas dentro do loteamento. Suas expressões são escritas como:

$$
\begin{aligned}
& t_{c}=18,628 \cdot \frac{L^{0,882}}{\alpha^{0,272}} \quad \text { (Método de Germano) } \\
& t_{c}=0,67 \cdot \frac{L^{0,24}}{\alpha^{0,26} \cdot S^{0,16}} \quad \text { (Método de Schaake) }
\end{aligned}
$$


Nas Equações (14) e (15), $t$ c é o tempo de concentração, calculado em minutos; $L$ é o comprimento axial do loteamento, definido como a distância em planta entre o ponto mais alto e a seção de controle, onde o escoamento é despejado na rede pública de águas pluviais. Seus valores devem ser inseridos em quilômetros, para ambas as fórmulas. $S$ é a declividade média do condomínio e $a$ é a porcentagem de área impermeável. Utilizando a planta do loteamento, disponibilizada em AutoCad, o comprimento axial levantado foi de $0,4908 \mathrm{~km}$; as frações de área impermeável, para os casos de telhado normal e telhado verde foram, respectivamente, $\mathrm{a}=53,63 \% \mathrm{e} \mathrm{a}=32,01$ $\%$; e o valor da declividade média do loteamento $(S)$ foi de $0,00954 \mathrm{~m} / \mathrm{m}$. Isto resultou nos tempos de concentração discriminados na Tabela 2.

Tabela 2 - Resumo dos tempos de concentração do loteamento para dois cenários de telhado.

\begin{tabular}{|c|c|c|}
\hline \multirow{2}{*}{ Tipo de telhado } & \multicolumn{2}{|c|}{ Tempo de concentração } \\
\cline { 2 - 3 } & Método de Germano & Método de Schaake \\
\hline Convencional impermeável & $3,383 \mathrm{~min}$ & $2,217 \mathrm{~min}$ \\
\hline Telhado verde com grama & $3,867 \mathrm{~min}$ & $3,783 \mathrm{~min}$ \\
\hline
\end{tabular}

Org. dos autores.

Tempos de concentração pequenos resultam em condições mais desfavoráveis, haja vista que permitem a acumulação mais rápida de água na saída do loteamento. Assim, levando em conta o caso mais crítico, a presente análise de eficiência hidrológica dos telhados verdes utilizou os valores estimados pelo Método de Schaake.

\section{Eficiência hidrológica dos telhados verdes para a} escala de loteamento

$$
E(\%)=100 \cdot(V N-V T V) / V N
$$

Na Equação (16), $E(\%)$ é a eficiência hidrológica percentual do telhado verde; $V N$ é o volume de escoamento superficial gerado na condição de telhado convencional; e VTV é o volume de escoamento superficial gerado com implantação de telhado verde em todas as edificações do loteamento. Os volumes de escoamento superficial gerados pelos eventos de chuva são estimados por integração numérica, calculando-se as áreas situadas abaixo dos hidrogramas.

\section{RESULTADOS E DISCUSSÃO}

Com o objetivo de estimar a faixa de variação
No presente trabalho, os hidrogramas induzidos pelo escoamento superficial foram simulados, utilizando a substituição hipotética de telhado convencional pela cobertura permeável com gramado superficial. Esta conversão foi implementada em todas as edificações do condomínio. A eficiência dos telhados verdes foi calculada a partir do volume de escoamento superficial que deixou de ser gerado, em comparação com a situação de telhado normal. A Equação (16) expressa o cálculo da eficiência hidrológica:

da eficiência hidrológica dos telhados verdes, este trabalho incluiu simulações com diferentes cenários vinculados a características da área intramuros e das chuvas. No primeiro caso, consideraram-se três condições de umidade antecedente do solo (condições I, II e III), permitindo varrer situações sazonais de solo seco a solo quase saturado, comuns ao longo de um ano hidrológico. Além disto, foram impostos dois cenários de uso do solo, representando a situação real e a hipotética, na qual o telhado convencional foi substituído, em $100 \%$ das edificações, por telhado verde. Para as precipitações, foram simuladas quatro distribuições temporais, representadas pelas curvas adimensionais 
Eficiência hidrológica de telhados verdes para a escala de loteamentos residenciais José Eduardo Alamy Filho, Igor Brito Costa Barcelos e Manna, Nágela Aparecida de Melo, Ana Clara Mendes Caixeta

de Huff, além de tempos de recorrência de 6 meses, $1,2,5,10,20,35,50,75$ e 100 anos. As durações das chuvas foram fixadas com valores mínimos iguais aos tempos de concentração do loteamento, nas situações real e hipotética, além de incluírem os intervalos de 10, 30, 60 minutos, 2,5,12,18 e 24 horas. A combinação destes diferentes cenários permitiu a realização de 1200 simulações, as quais foram alimentadas com eventos de chuvas com duração máxima de um dia. São tormentas como estas, intensas e relativamente curtas, que comumente sobrecarregam o sistema de drenagem urbana.

A Figura 4 ilustra as isolinhas de eficiência hi- drológica obtidas a partir das simulações. Note-se que, em linhas gerais, os telhados verdes tendem a ser mais eficientes para chuvas de pequena altura pluviométrica e curta duração. Além disto, há uma ampla faixa de variação de eficiência, cujos valores são interdependentes das condições de umidade antecedente do solo. De uma forma geral, as simulações evidenciaram que os telhados verdes são mais eficientes para situações de solo seco (condição I), recorrentes durante períodos de estiagem. Entretanto, nas estações chuvosas, principalmente após dias de chuvas consecutivas, quando a saturação do solo fica iminente, os telhados verdes visivelmente perdem eficiência hidrológica.

Figura 4 - Linhas de eficiência hidrológica dos telhados verdes, considerando diferentes situações de umidade antecedente do solo.

\section{Eficiência (\%) para condição de umidade I}

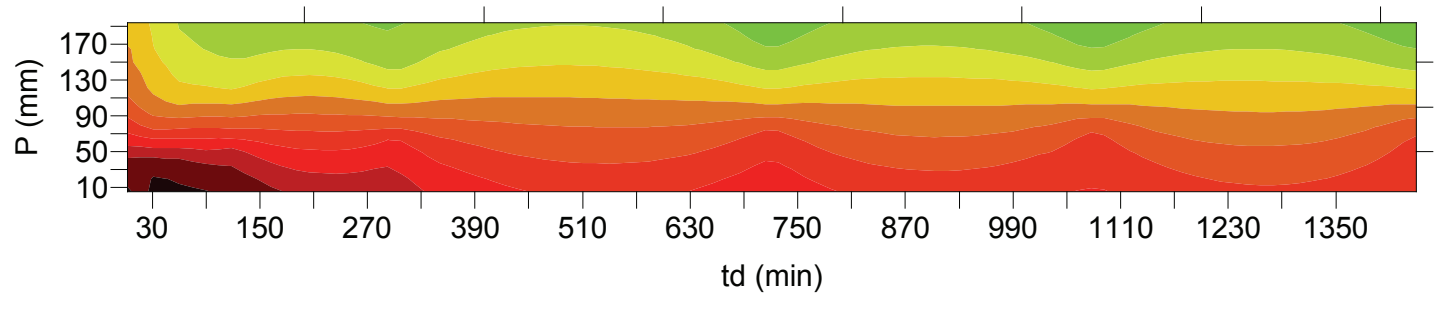

Eficiência (\%) para condição de umidade II

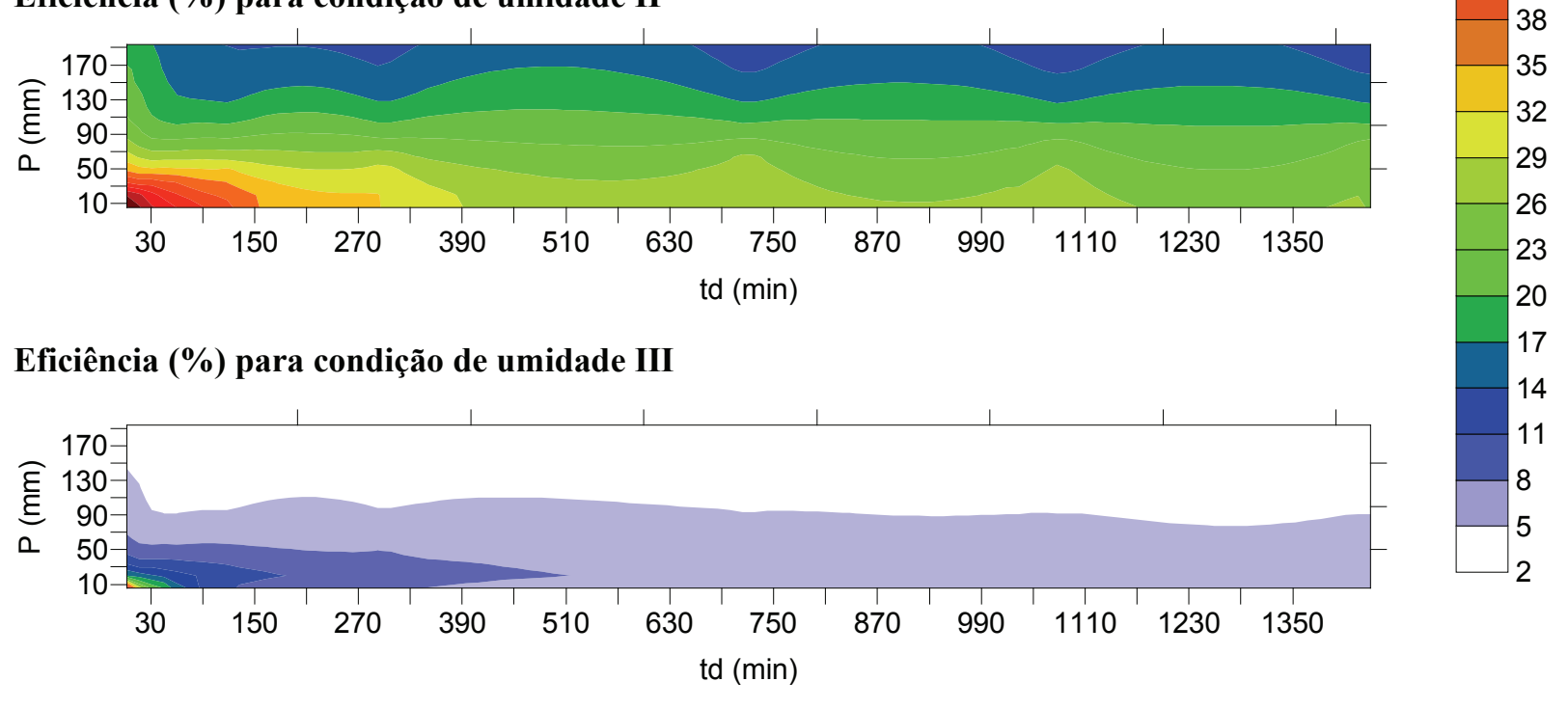

Org. dos autores.

A faixa de variação da eficiência do telhado verde, para diferentes condições de umidade do solo, também pode ser ilustrada pela Figura 5 , a qual resume estatisticamente os resultados na forma de gráficos box-plot. Os resultados corroboram a influência das condições de umidade do solo sobre a eficiência hidrológica da cobertura permeável. 
Figura 5 - Eficiências hidrológicas máximas, mínimas, médias e limites do terceiro e primeiro quartis.

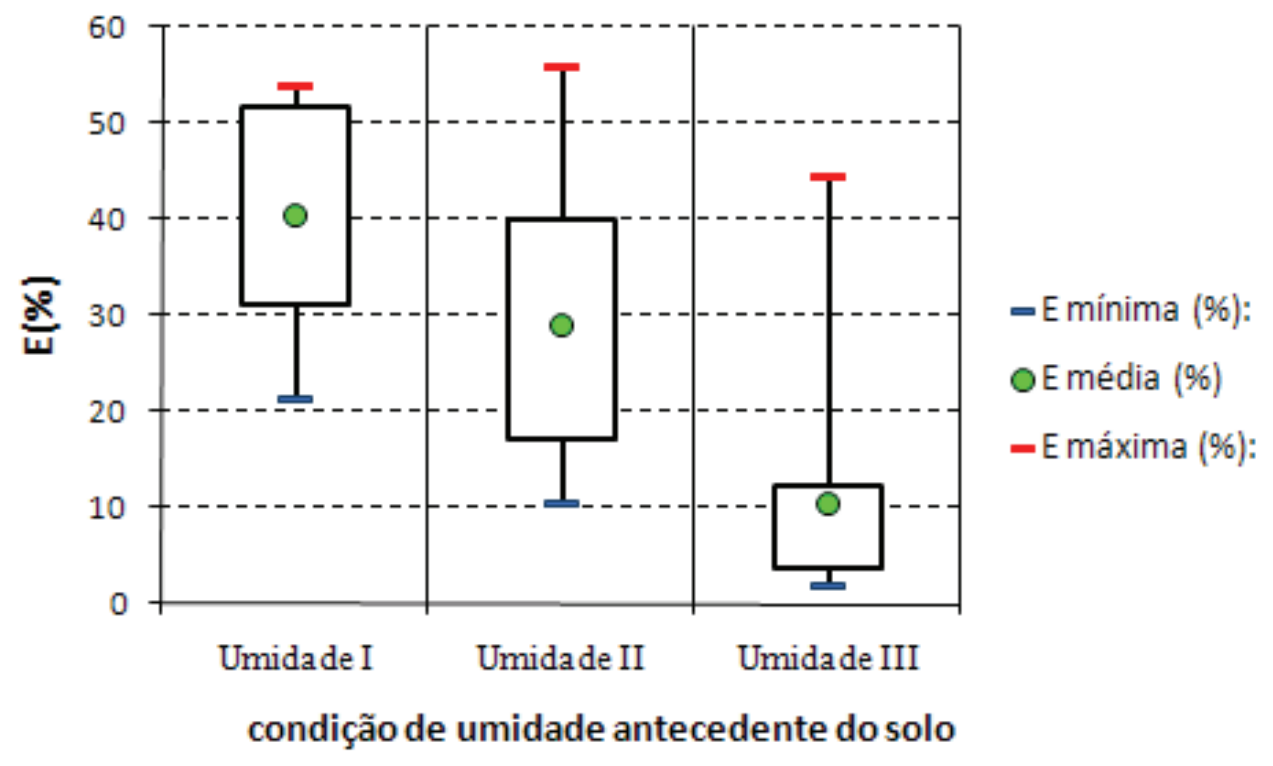

Org. dos autores.

As eficiências médias são reduzidas com o aumento da umidade antecedente do solo. Seus valores passam de 40,35\%, na condição de solo seco (I) para $10,44 \%$, na condição de saturação iminente (III). Estas tendências de queda também são verificadas para as eficiências que limitam os primeiros e terceiros quartis de cada situação. Especificamente para as condições normais (II) e de solo seco (I), a relativa equidistância entre os valores médios e os limites dos primeiros e terceiros quartis sugere que as eficiências médias são pouco influenciadas pelos resultados máximos e mínimos, tendendo a representar adequadamente a capacidade dos telhados verdes de limitação do escoamento superficial.

A eficiência mínima global foi de $2,02 \%$, obtida na condição de solo úmido, para chuva de 100 anos de recorrência, $24 \mathrm{~h}$ de duração e hietograma tipo 4. Este cenário gerou uma altura pluviométrica de 193,7 mm despejada em apenas 1 dia. Isto revela que a combinação de solo úmido com chuvas de grande altura pluviométrica tende a reduzir sensivelmente a eficiência hidrológica dos telhados verdes. A eficiência máxima global de 55,67\% foi estimada para a condição de solo normal, com chuva de 20 anos de recorrência, hietograma tipo 4 e duração equivalente ao tempo de concentração do loteamento com telha- dos convencionais. Este valor superou ligeiramente a eficiência máxima de $53,81 \%$ verificada para solo inicialmente seco. Para solo seco e chuvas de curta duração, o terreno apresenta grande capacidade de infiltração. Esta combinação reduz, de maneira tênue, a influência relativa e isolada dos telhados verdes como reguladores do escoamento superficial. A despeito disto, quando tormentas de mesmo tempo de recorrência adquirem durações maiores, as eficiências hidrológicas decaem independentemente da condição do solo ou da distribuição temporal da chuva.

A Figura 6 ilustra as variações temporais da precipitação e do índice de infiltração para as situações onde foram estimadas as menores e maiores eficiências globais. Na situação de eficiência mínima, a infiltração representa uma parcela ínfima da chuva. Isto permite uma considerável conversão da chuva em escoamento superficial. Neste contexto, considerando telhados convencionais, a chuva excedente representa cerca de $98 \%$ da precipitação. Ainda nesta situação, a implantação das coberturas vegetais reduz este índice para $96 \%$. Trata-se de uma queda proporcionalmente pequena. Por outro lado, nos cenários de eficiência máxima global, caracterizado por um evento de curta duração (2,217 minutos), quase toda a chuva é convertida em infiltração. Isto faz com que o escoamento 
Eficiência hidrológica de telhados verdes para a escala de loteamentos residenciais José Eduardo Alamy Filho, Igor Brito Costa Barcelos e Manna, Nágela Aparecida de Melo, Ana Clara Mendes Caixeta

superficial represente apenas $6,5 \%$ do total precipitado. Esta tendência torna-se mais evidente quando há a implantação dos telhados verdes, o que reduz drasticamente este índice para $0,5 \%$.

As eficiências hidrológicas também podem ser confrontadas com parâmetros individuais das chuvas, de maneira a identificar o grau de relação entre eles. A Tabela 3 resume o coeficiente de correlação (r) para diferentes pares de valores. Neste caso, a altura pluviométrica apresentou correlações negativas classificadas como muito fortes (de -1 a $-0,9$ ), para condições de umidade I e II, e correlações negativas fortes (de -0,89 a -0,70), para condição de umidade III. Estas expressivas correlações negativas indicam que o aumento da altura pluviométrica redunda na queda imediata da eficiência hidrológica dos telhados verdes. Esta influência é tão marcante quanto mais seco estiver o solo. A análise com a intensidade de precipitação revelou correlações positivas fortes (de 0,7 a 0,89 ) com a eficiência hidrológica. Todavia, as correlações com o tempo de recorrência das chuvas foram negativas e notadamente fracas (de $-0,39$ a $-0,20)$.

Figura 6 - Hidrogramas e hietogramas para as situações de eficiência hidrológica global mínima (a) e máxima (b).

(a) $\mathrm{E}_{\min }(\%)=2,02 \% ; \operatorname{Tr}=100$ anos, duração de 24 horas, chuva tipo 4 , condição de umidade III

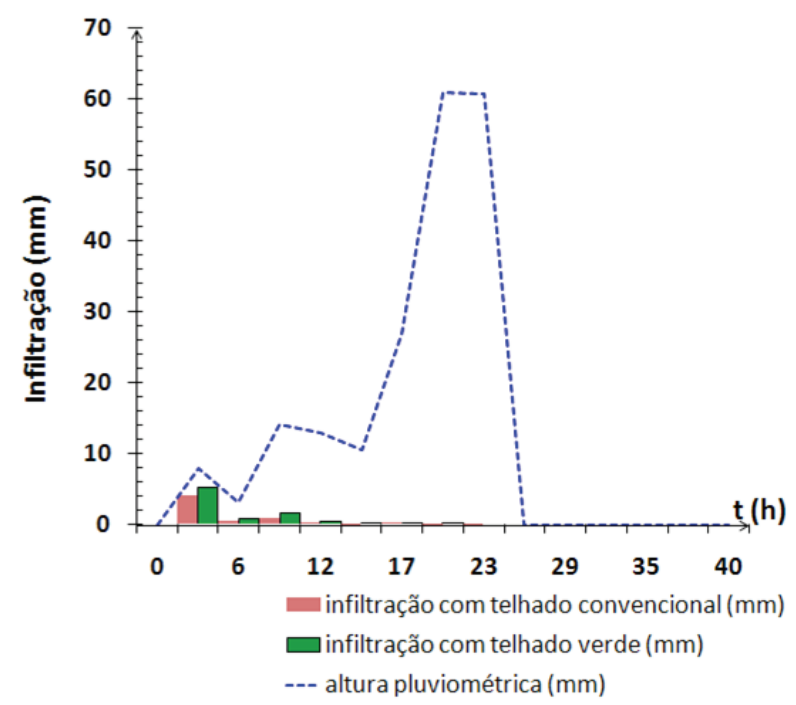

(b) $\mathrm{E}_{\text {máx }}(\%)=55,67 \%$; $\operatorname{Tr}=20$ anos, duração de 2,217 minutos, chuva tipo 4 , condição de umidade II

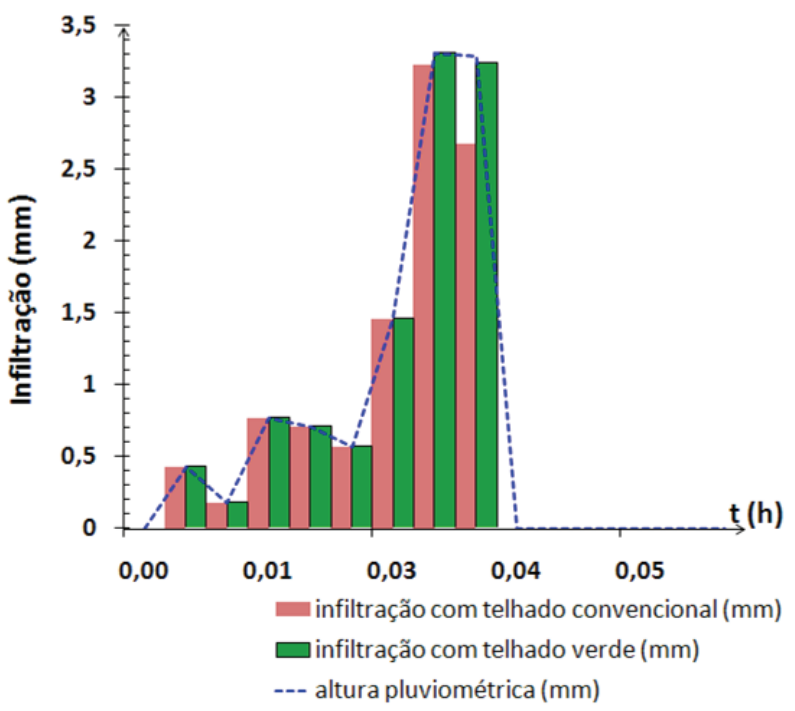

Org. dos autores

Tabela 3 - Coeficientes de correlação entre a eficiência hidrológica das coberturas verdes e parâmetros das precipitações.

\begin{tabular}{|c|c|c|c|}
\hline & $E(\%) \boldsymbol{x} \boldsymbol{P}(\mathbf{m m})$ & $\boldsymbol{E}(\%) \boldsymbol{x} \boldsymbol{i}(\mathbf{m m} / \mathbf{h})$ & $\boldsymbol{E}(\%) \boldsymbol{x} \boldsymbol{T r}($ anos $)$ \\
\hline condição de umidade I & $-0,98$ & 0,74 & $-0,35$ \\
\hline condição de umidade II & $-0,92$ & 0,81 & $-0,24$ \\
\hline condição de umidade III & $-0,72$ & 0,7 & $-0,20$ \\
\hline
\end{tabular}

Org. dos autores. 
Eficiência hidrológica de telhados verdes para a escala de loteamentos residenciais

José Eduardo Alamy Filho, Igor Brito Costa Barcelos e Manna, Nágela Aparecida de Melo, Ana Clara Mendes Caixeta

Quando as relações entre as variáveis são plotadas em gráficos de dispersão (Figura 7) evidencia-se um padrão de comportamento bem definido entre a eficiência hidrológica e a altura pluviométrica - Figura 7(a). Nota-se, sobretudo, que este comportamento é independente da distribuição temporal da chuva. Para os outros parâmetros, entretanto, não há um modelo de variação muito claro.

Figura 7 - Gráficos de dispersão entre a eficiência hidrológica dos telhados verdes e parâmetros de precipitação.

(a)

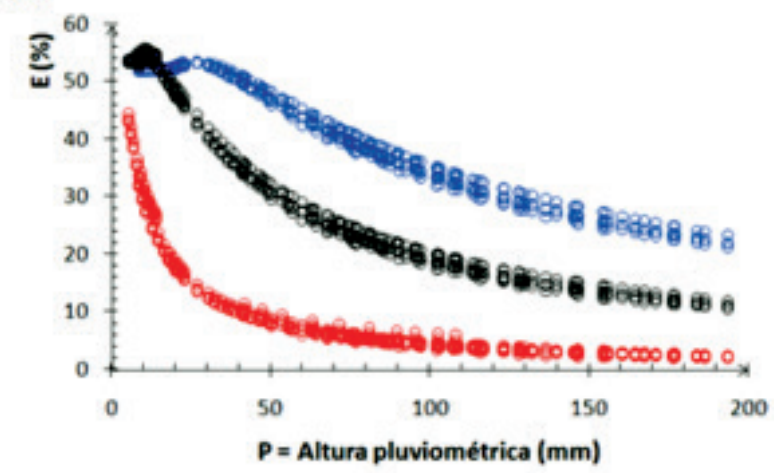

(c)

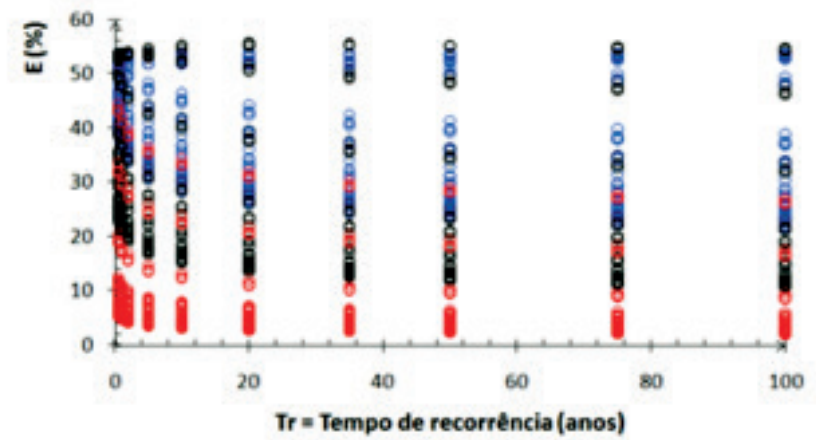

(b)

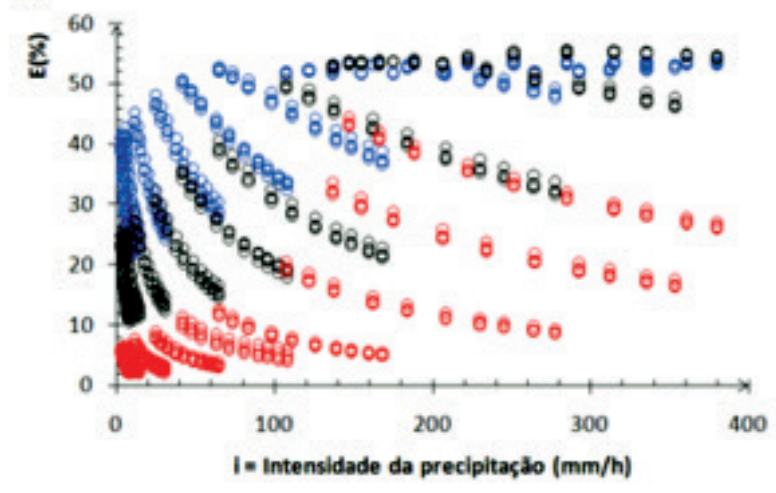

(d)

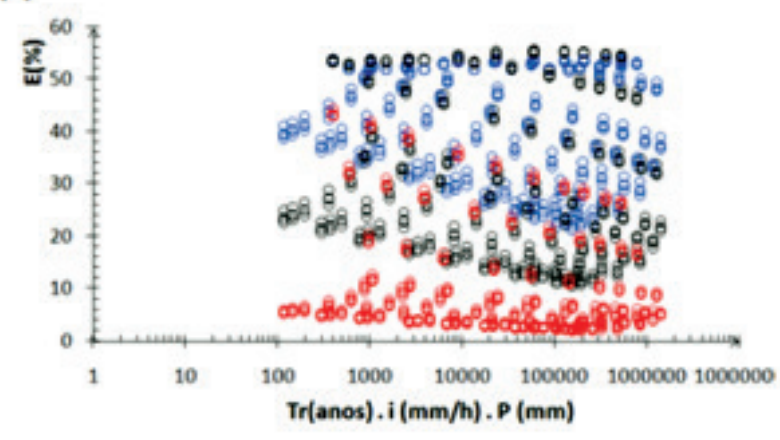

o- umidade I; o - umidade II; $\mathbf{0}$ - umidade III

Org. dos autores.

As fortes correlações e o comportamento bem determinado entre a eficiência hidrológica e a altura pluviométrica propiciaram a construção de linhas de tendência relativamente precisas. Estas funções permitem estimar a capacidade de atenuação do escoamento superficial, diante da substituição de telhados convencionais por telhados verdes em todas as edificações do loteamento. Assim, relações mais diretas entre a eficiência hidrológica e a precipitação, podem ser fornecidas pelas Equações (17 a 19). Estas expressões constituem os melhores ajustes para os resultados da Figura 7(a), uma vez que apresentaram os coeficientes de determinação $\left(R^{2}\right)$ mais próximos de 1 . 
Eficiência hidrológica de telhados verdes para a escala de loteamentos residenciais

José Eduardo Alamy Filho, Igor Brito Costa Barcelos e Manna, Nágela Aparecida de Melo, Ana Clara Mendes Caixeta

$$
E(\%)=-1,3465 \cdot 10^{-7} \cdot P^{4}+5,9930 \cdot 10^{-5} \cdot P^{3}-8,3675 \cdot 10^{-3} \cdot P^{2}+1,9144 \cdot 10^{-1} \cdot P+51,963
$$

(17) (para condição I, de solo inicialmente seco, com $\mathrm{R}^{2}=0,992$ )

$$
\begin{gathered}
E(\%)=-4,1802 \cdot 10^{-11} \cdot P^{6}+2,5973 \cdot 10^{-8} \cdot P^{5}-6,1691 \cdot 10^{-6} \cdot P^{4}+6,8633 \cdot 10^{-4} \cdot P^{3}+ \\
-3,2854 \cdot 10^{-2} \cdot P^{2}+4,5872 \cdot 10^{-2} \cdot P+56,192
\end{gathered}
$$

(18) (para condição II, de solo normal, com $R^{2}=0,995$ )

$$
E(\%)=2,4325 \cdot 10^{-2} \cdot P^{-0,87669}
$$

Salienta-se que as Equações (17 a 19) foram construídas para o caso específico do loteamento estudado. Para outras áreas, devem-se gerar resultados que conduzirão a equações diferentes. Nestas expressões, a única variável independente é a altura pluviométrica $(P)$, que deve ser substituída em milímetros. Isto possibilita uma avaliação expedita da eficiência hidrológica das coberturas verdes diante de sua implantação em todas as edificações de um condomínio.

\section{CONCLUSÃO}

Os resultados das simulações hidrológicas deste trabalho indicaram que a implantação de telhados verdes, nas edificações de condomínios, pode apontar para reduções consideráveis do volume de escoamento superficial. Com os cenários de precipitação impostos no loteamento selecionado, encontrou-se eficiência máxima global de 55,67\%. Para condições de solo inicialmente seco, que são comuns após estiagens, estimou-se uma eficiência hidrológica média de $40,35 \%$, a qual se reduz para $29,05 \%$ com o aumento da umidade do solo (condição normal), chegando a $10,44 \%$ em situações de saturação iminente. A despeito da sua dependência da umidade antecedente do solo, este potencial de redução do escoamento superficial é considerável. Assim, a implantação de telhados verdes atenua as vazões de pico geradas na saída do loteamento, aliviando o sistema público de microdrenagem e, num contexto mais amplo, reduzindo os riscos de enchentes ribeirinhas nos fundos de vale. Entretanto, esta eficiência hidrológica é reduzida drasticamente para condições em que o solo apresenta-se úmido e quase saturado.

Para uma mesma condição de umidade do solo, as eficiências hidrológicas do telhado verde
(19) (para condição III, de solo úmido, com $R^{2}=0,985$ )

pouco variaram para os diferentes hietogramas impostos, indicando que a distribuição temporal da chuva causa pouca influência na atenuação do escoamento superficial. Por outro lado, características da precipitação demonstraram-se decisivas. Neste contexto, destaca-se primordialmente a altura pluviométrica, que apresentou correlações negativas muito fortes com a eficiência hidrológica. Secundariamente, a intensidade de precipitação apresentou fortes correlações positivas. As correlações com o tempo de recorrência foram consideradas fracas. Apesar disto, um padrão de comportamento apenas foi verificado entre a eficiência hidrológica e a altura pluviométrica, fato que permitiu a construção de equações de tendência relativamente precisa, com coeficientes de determinação muito próximos da unidade.

Ressalta-se que a despeito da sua eficiência hidrológica e da contribuição indireta para alívio do sistema de drenagem urbana, a opção arquitetônica pela cobertura verde é controversa em outros aspectos. Dentre estes, cita-se o custo da edificação, basicamente norteado pela exigência de estruturas mais robustas, além da possibilidade de surgirem problemas decorrentes de umidade, como infiltrações na laje superior. Apesar da prevenção destes riscos com técnicas de impermeabilização, não há como anular completamente a probabilidade de infiltração. Tal risco é evidentemente maior do que nos telhados impermeáveis convencionais, os quais, em vez de reterem água, favorecem o escoamento mais direto para fora da projeção horizontal do edifício.

O presente estudo, embora aplicado para um condomínio específico, apresenta uma metodologia geral e de implementação computacional razoavelmente simples, que pode ser aplicada em nível de zona urbana, de bairro e na escala mínima de loteamento. 
Eficiência hidrológica de telhados verdes para a escala de loteamentos residenciais

José Eduardo Alamy Filho, Igor Brito Costa Barcelos e Manna, Nágela Aparecida de Melo, Ana Clara Mendes Caixeta

\section{REFERÊNCIAS}

BALDESSAR, S. M. N. Telhado verde e sua contribuição na redução da vazão da água pluvial escoada. 2012. 124 f. Dissertação (Mestrado em Engenharia da Construção Civil) - Universidade Federal do Paraná, Programa de Pós-Graduação em Engenharia de Construção Civil, Curitiba, 2012.

FRANSCICHETI, M. M.; ALAMY FILHO, J. E. Equação de intensidade-duração-frequência e distribuição temporal das chuvas intensas para o município de Uberlândia aplicado na estimativa de vazões críticas geradas em lotes. In: Simpósio Brasileiro de Recursos Hídricos, 19, 2011, Maceió, Anais... Maceió: ABRH, 2011. Disponível em: <http://www.abrh.org. $\mathrm{br} / \mathrm{SGCv} 3 /$ UserFiles/Sumarios/4bd89d583f2ac1bc 70067500d1c52f00_055e0d39e1490656c99c58d5 cd014028.pdf $>$. Acesso em: out. 2014.

FRANCISCHET, M. M. Análise da influência dos reservatórios de detenção domiciliares no escoamento superficial urbano. 2012. 195 f. Dissertação (Mestrado em Engenharia Civil) - Universidade Federal de Uberlândia, Uberlândia, 2012.

JOHNSTON, C.; McCREARY, K.; NELMS C. Vancouver public library green roof monitoring project, GREENING ROOFTOPS FOR SUSTAINABLE COMMUNITIES CONFERENCE, 2, Portland, pp. 391-403, 2004.

KOLB, W. Good reasons for roof planting - Green roofs and rainwater. In: CONFERENCE ON URBAN HORTICULTURE, Acta Horticulturae, n.643, pp. 295-300, 2004. Disponível em: < http://wwwlib. teiep.gr/images/stories/acta/Acta\%20643/643_38. pdf $>$. Acesso em: out. 2014. DOI: 10.17660/ActaHortic.2004.643.38

McCUEN, R.H. Hydrologic analysis and design. New Jersey: Prentice Hall, 1998.
MORAN, A.; HUNT, B.; JENNINGS, G. A North Carolina field study to evaluate greenroof quantity, runoff quality, and plant growth, GREENING ROOFTOPS FOR SUSTAINABLE COMMUNITIES CONFERENCE, 2, Portland, pp. 446-460, 2004.

NISHIYAMA, L.; FONSECA, F.G.; Comportamento da dispersibilidade de solos argilosos das chapadas da região de Uberlândia. In: Simpósio Regional de Geografia, 2, 2003, Uberlândia, Anais... Uberlândia, 2003.

PALLA, A. et al. Modelling storm water control operated by green roofs at the urban catchment scale. In: International Conference on Urban Drainage, 21, Edinburgh, Scotland, UK, pp. 1-10, 2008. Disponível em: $<$ http://web.sbe.hw.ac.uk/staffprofiles/bdgsa/11th International_Conference_on_Urban_Drainage_CD/ ICUD08/pdfs/245.pdf $>$. Acesso em: out. 2014.

SCS. SOIL CONSERVATION SERVICE. SCS National Engineering Handbook, Sec 4, Hydrology, USDA, USA, 1972.

STOVIN, V.; DUNNETT, N.; HALLAM, A. Green roofs - getting sustainable drainage off the ground. Novatech, pp. 1-8, 2007. Disponível em: < http://www. greenroofresearch.co.uk/ hydro/Stovin $\% 20$ et $\% 20$ al_2007_Green\%20roofs_getting\%20sustainable $\% 20$ drainage $\% 20$ off $\% 20$ the $\% 20$ ground(Novatech $\% 20$ Green\%20Roofs).pdf $>$. Acesso em: out. 2014.

STUBCHAER, J.M. The Santa Barbara urban hydrograph method. Proceedings of the National Symposium of Hydrology and Sediment Control, 1980, Lexington, New York, USA, Anais... Lexington, 1980.

TOMAZ, P. Cálculos hidrológicos e hidráulicos para obras municipais. São Paulo: Saraiva, 2002. 